\title{
Can Superior Saggital Sinus Density Predict Anemia?
}

\author{
Deepti B Srinivas ${ }^{1}$, Dhritiman Chakrabarti ${ }^{1}$, Shriram Varadarajan ${ }^{2}$, Pavithra Venkateswaran $^{3 *}$, Kaustuv Dutta $^{1}$ \\ and Manjunatha Lakshmegowda ${ }^{1}$
}

${ }^{1}$ Department of Neuroanaesthesia and Neurocritical Care, National Institute of Mental Health and Neuro Sciences, India

${ }^{2}$ Dept of Neuroradiology, Christian Medical College \& Hospital, Ludhiana, India

${ }^{3}$ Department of Anaesthesia, M.S. Ramaiah Medical College, India

Submission: March 28, 2018; Published: April 06, 2018

*Corresponding author: Pavithra Venkateswaran, Department of Anaesthesia, M.S. Ramaiah Medical, College, Bangalore, Karnataka, India, Tel: 7022044720; Email: drpavithrav@gmail.com
Abstract SSS is not known. With this study we aimed to:
a. Find the contribution of leucocytes and platelets to the SSS density.
b. Compare two methods of determination of SSS density for predictability of $\mathrm{Hb}$.
c. Derive an equation to predict $\mathrm{Hb}$ from SSS density and validate the equation.
d. Find a cut-off of SSS density for prediction of anemia.

Introduction: Correlation of density of superior saggital sinus (SSS) on computed tomography (CT) scan with hematocrit and haemoglobin ( $\mathrm{Hb})$ has been described previously. However, the extent of contribution of total leucocyte count (TLC) and platelet count (PC) to the density of

Methodology: Retrospective data from electronic database was collected concurrently for all traumatic brain injury (TBI) patients operated within a 4 month period ( $\mathrm{n}=71$ ) which included $\mathrm{Hb}$, TLC, PC and SSS density on CT scan. Maximum and average SSS density in Hounsfield units (HU) was collected in two ways-insides a triangle outlining the SSS excluding dura edge (Tmax/Tmean) or inside a circle of $0.03-0.05 \mathrm{~cm} 2$ at centre of the SSS (Cmax/Cmean). Spearman's correlation was used to explore associations between CT scan and haematological data. Linear Regression was used to find independent predictors of $\mathrm{Hb}$ among the significant correlations. A separate cohort of 91 samples was used to validate the derived regression equation and Bland Altman plot was constructed. Receiver operating characteristic (ROC) curve was used to find cut-off of the independent predictors for diagnosing $\mathrm{Hb}$ less than $10 \mathrm{gm} \%$.

Results: The Tmax, Tmean, Cmax and Cmean had significant correlation with Hb with correlation co-efficient of $0.335,0.349,0.416$ and 0.445 respectively. TLC and PC were not significantly associated with any CT scan density parameters. Linear regression revealed only Cmean to be independently predictive of $\mathrm{Hb}(\mathrm{p}=0.017)$. Regression equation derived was $[\mathrm{Hb}=9.142+0.89 * \mathrm{Cmean}]$. Bland Altman plot of observed $\mathrm{Hb} v \mathrm{~s}$ calculated $\mathrm{Hb}$ found no significant difference between the two with mean difference of $0.11 \pm 1.996$. The limits of agreement were 4.1 to -3.88 . Area under the ROC curve for Cmean as a predictive test of $\mathrm{Hb}$ was 0.791 ( $\mathrm{p}=0.003$ ) and the Cmean of $44.83 \mathrm{HU}$ predicted $\mathrm{Hb}<10 \mathrm{gm} / \mathrm{dl}$ with $80 \%$ sensitivity and $76 \%$ specificity.

Conclusion: The following conclusions can be derived:

a. TLC and PC do not appear to influence the density in SSS on CT scan in TBI patients-probably because of sheer quantity and mass of RBCs compared to leucocytes and platelets respectively.

b. Mean density of central circular area of SSS was independently predictive of Hb-probably because slow flow in the SSS facilitates laminar flow pattern with cellular component concentrated in the central part.

c. Limits of agreement between observed $\mathrm{Hb}$ and calculated $\mathrm{Hb}$ of 4.1 to -3.88 are too large to be ignored from clinical perspective. Thus predicting $\mathrm{Hb}$ from Cmean wouldn't be useful in clinical practice.

d. The cut-off of $44.83 \mathrm{HU}$ for $\mathrm{Hb}<10 \mathrm{gm} / \mathrm{dl}$ would be clinically helpful in predicting need for blood transfusion if $\mathrm{Hb}$ value is not available readily.

Keywords: Anemia; Superior saggital sinus; Traumatic brain injury

Abbreviations: SSS: Superior Saggital Sinus; Hb: Haemoglobin; TLC: Leucocyte Count; PC: Platelet Count; TBI: Traumatic Brain Injury; EDH: Extradural Hemorrhage; CT: Computed Tomographic 


\section{Introduction}

Traumatic brain injury (TBI) cases with operable intracranial hematomas constitute neurosurgical emergencies. The risk of neurological deterioration with untreated extradural hemorrhage (EDH) and attended increase in mortality and morbidity entails swift action and evacuation of hematoma. At our hospital the usual time duration from diagnosis of EDH to entry into operation theatre is 20-30 minutes. During this time duration patient undergoes intravenous cannulation with blood sampling for hemogram (haemoglobin (Hb) level, total leucocyte count (TLC) and platelet count (PC)) and blood biochemistry testing, part preparation and medication administration as per orders and protocol. However, logistical difficulties prove a hindrance in blood sample processing and timely notification of the hemogram and blood biochemistries to the anaesthesiologist managing the case. The importance of knowledge of $\mathrm{Hb}$ level of such a patient to an anesthesiologist cannot be overstated. Timely decisions regarding ordering blood products from blood bank are of utmost importance in TBI patients. It is a known fact the hematocrit influences the signal attenuation within vasculature on computed tomographic (CT) scans [1]. This study was designed to use the degree of signal attenuation of intracranial vasculature to predict the level of $\mathrm{Hb}$ of the patient. Furthermore, we tried to elucidate the best method for obtaining the signal attenuation values. The effect of TLC and PC on the attenuation values was also studied.

\section{Methodology}

This was a retrospective, single centre, observational study conducted after obtaining approval from the institutional ethics committee (consent waiver was applied for and granted). Institutional electronic record database (E-hospital@NIC, Hospital Management system) was used to obtain brain CT scan images and preoperative Hb level, TLC and PC for adult patients (18-65 years) of either sex arriving in the casualty with TBI requiring surgery over a four month period $(n=71)$. Patients with intracranial haematomas involving the superior sagittal sinus (SSS) or those with no viable vasculature on CT scan for density measurement were excluded.

\section{Superior sagittal sinus density measurement}

The CTs were firstly aligned according to anterior commissure - posterior commissure line. The vascular structure chosen for the signal attenuation measurement was the SSS, due to its uniform presence in all patients. Basilar artery density was also obtained. The density measurement of SSS was obtained (using InstaRISPACS, Meddiff Technologies Pvt Ltd.) on axial sections of CT brain at the level of the third ventricle or, if poorly visualized, in $5 \mathrm{~mm}$ rostral or caudal axial sections in Hounsefeld units (HU). The maximum and mean density measurements were obtained using 2 methods (Figure 1A \& 1B):

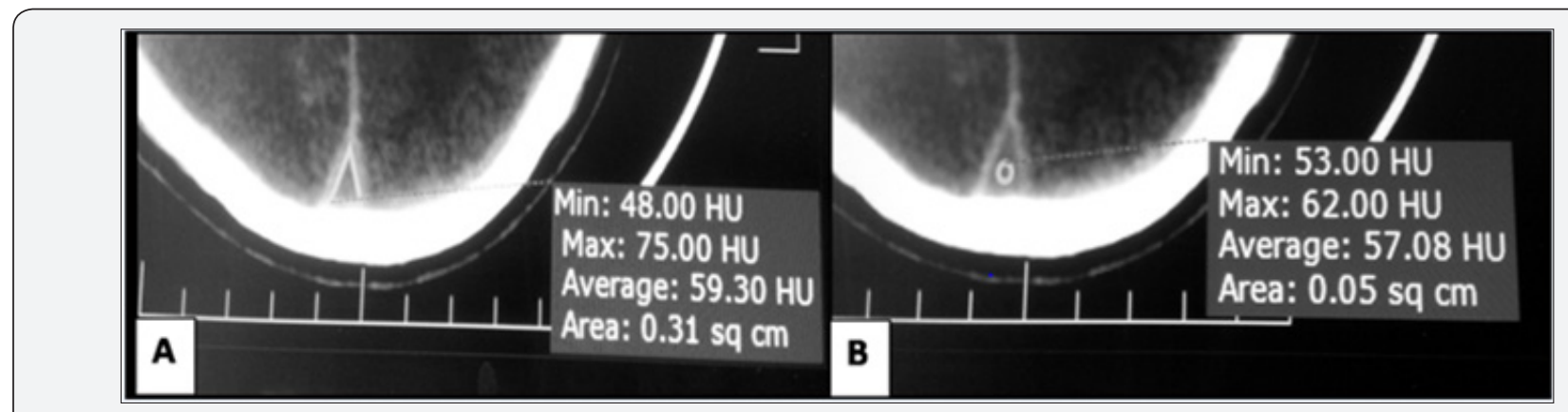

Figure 1: Showing placement of region of interest in triangular (A)and circular(B)fashion to record the maximum and the mean signal density in the superior sagittal sinus.

a. Triangular region of interest (ROI) outlining the SSS but excluding dural edge (Tmax, Tmean),

b. Circular ROI of area $0.03-0.05 \mathrm{~cm}^{2}$ at the centre of SSS (Cmax, Cmean).

Earlier studies have used the circular ROI method for measuring the SSS density [2]. The triangular method was designed to try and include the whole vascular structure, to account for the effect of variation in flow velocities of red blood cells in centre of the SSS stream and those in the peripheries due to gradient in shear rate acting on red blood cells (RBC). The values obtained from this cohort were used to derive a regression equation to predict $\mathrm{Hb}$ values from the density measurements. A separate cohort of such patients $(n=91)$ was randomly chosen over a separate one year period distinct from the previous cohort, for validation of the derived regression formula.

\section{Statistical analysis}

Normality of the quantitative data was tested using ShapiroWilk test. Spearman's correlation was used to explore associations between CT scan and haematological data, due to Tmean and $\mathrm{Hb}$ values being non-normally distributed. Linear regression was used to find independent predictors of $\mathrm{Hb}$ among the significant correlations and derive predictive equation. Bland Altman plot was constructed to find predictive accuracy of equation derived $\mathrm{Hb}$ values in the validation cohort. Receiver operating characteristic (ROC) curve was constructed to find cut-off of the independent predictors for diagnosing $\mathrm{Hb}$ less than $10 \mathrm{gm} \%$. $\mathrm{P}<0.05$ was taken as significance level for all calculations. 


\section{Results}

Data of 71 patients of the first cohort was analyzed. It comprised of 61 males and the age was $39.17 \pm 15.42$ (Mean \pm standard deviation in years). Correlation analysis showed only $\mathrm{Hb}$ levels to be significantly correlated with all the CT scan parameters (Cmax, Cmean, Tmax, Tmean), with the circular ROI parameters being more strongly correlated than the triangular ROI ones, and highest coefficient being for Cmean (Table 1 \& Figure 2). The four CT scan parameters were entered into a linear regression model for prediction of $\mathrm{Hb}$ level, which revealed only Cmean to be independently predictive $(\mathrm{p}=0.017)$. Formula for calculation of $\mathrm{Hb}$ from $C$ mean was derived by univariate linear regression.

Haemoglobin $=9.142+0.089 *$ Cmean $(\mathrm{p}<0.001 ; R 20.175)$

This derived formula was then used to calculate predicted $\mathrm{Hb}$ values from Cmean of the validation cohort data, which were compared against observed $\mathrm{Hb}$ values using Bland Altman plot. Analysis revealed a mean difference of $0.11 \mathrm{gm} / \mathrm{dl}(\mathrm{p}=0.599$, for comparison of mean difference from 0 ) between observed and calculated values with limits of agreement being -3.88-4.11 gm/dl (Figure 3). Due to the wide limits of agreement, clinical utility of the regression formula for calculating exact $\mathrm{Hb}$ level was discounted and ROC curve was constructed for Cmean to predict anemia (observed $\mathrm{Hb}<10 \mathrm{gm} / \mathrm{dl}$ ). The area under the ROC curve was 0.791 ( $\mathrm{p}=0.003,95 \%$ confidence intervals $0.588-0.994$ ). A Cmean of 44.83 predicted anemia with sensitivity of $80 \%$ and specificity of $76 \%$ (Figure 4).

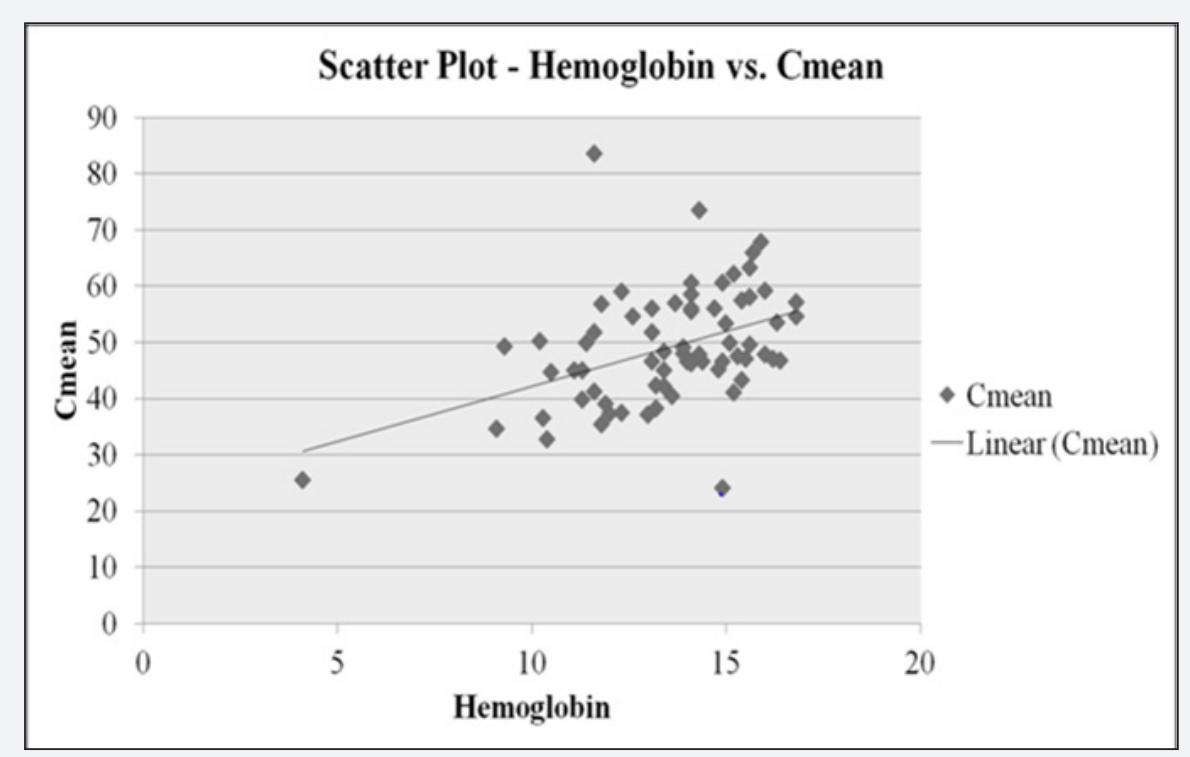

Figure 2 : Showing scatter plot of Cmean with haemoglobin level.

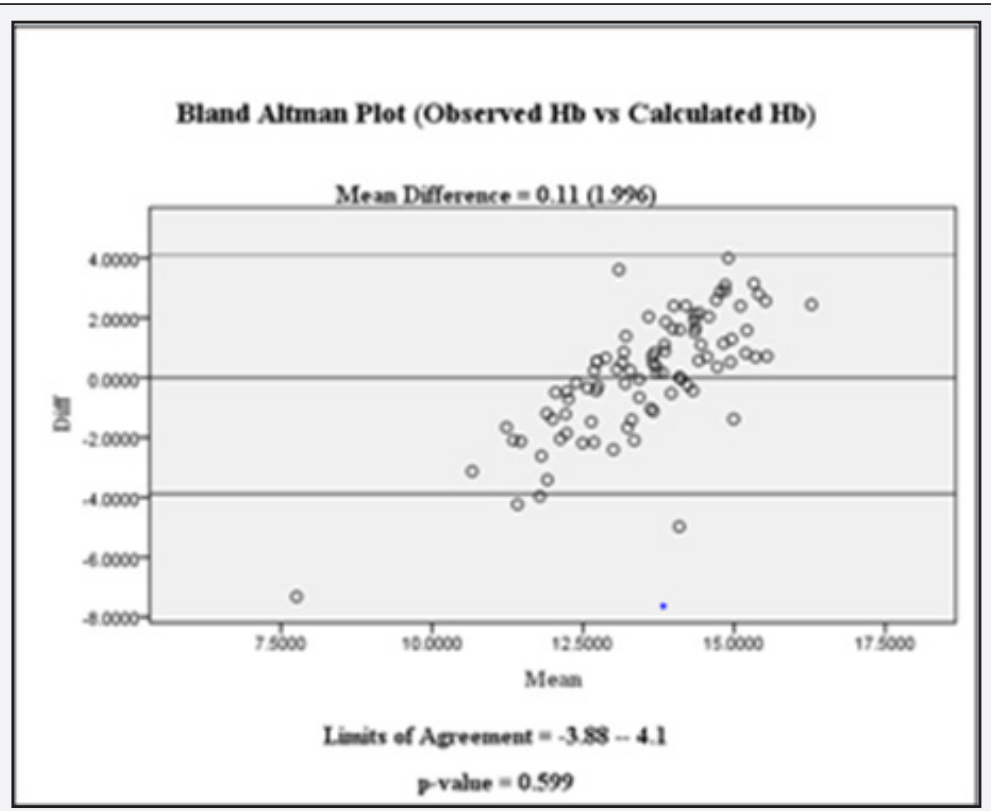

Figure 3 : Bland Altman plot for observed and predicted haemoglobin values. 


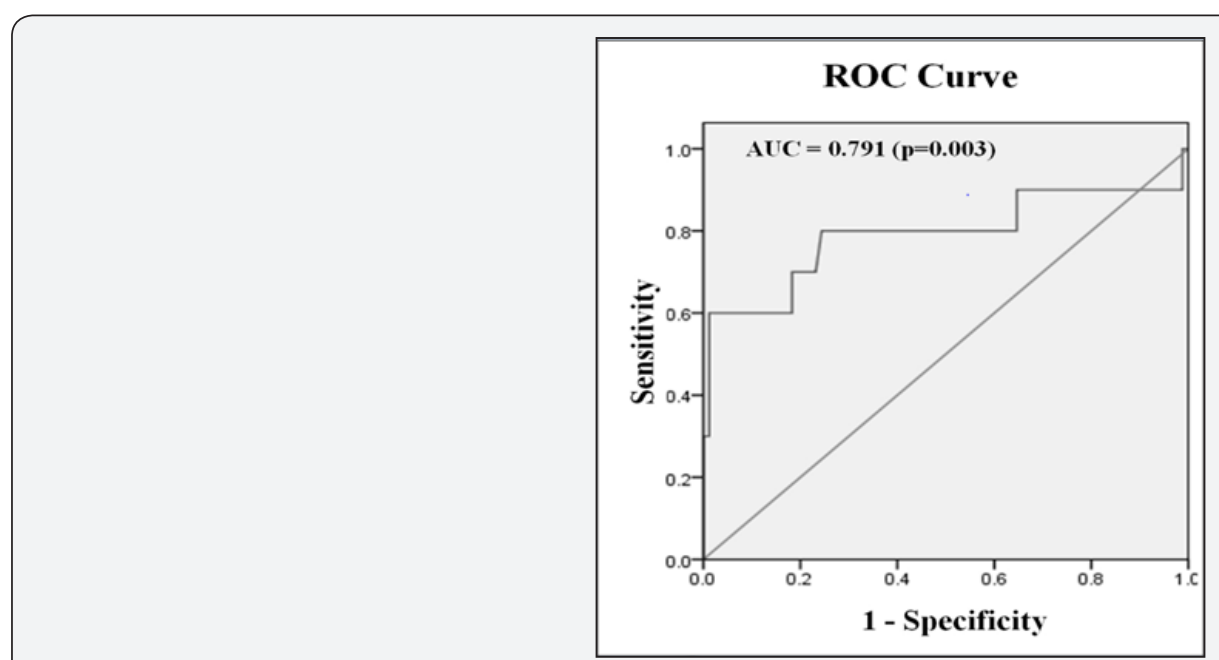

Figure 4 : Receiver operating characteristic curve of Cmean for prediction of anemia.

Table 1: Showing correlation coefficients of CT scan and haematological parameters.

\begin{tabular}{|c|c|c|c|}
\hline $\begin{array}{c}\text { CT Scan } \\
\text { Parameter }\end{array}$ & $\begin{array}{c}\text { Haemoglobin } \\
\text { Level }\end{array}$ & $\begin{array}{c}\text { Total } \\
\text { Leucocyte } \\
\text { Count }\end{array}$ & Platelet Count \\
\hline Tmax & $.335^{*} \AA$ & 0.213 & 0.083 \\
\hline Tmean & $.349^{*}$ & 0.22 & 0.099 \\
\hline Cmax & $.416^{*}$ & 0.195 & 0.122 \\
\hline Cmean & $.445^{*}$ & 0.159 & 0.106 \\
\hline
\end{tabular}

Significant correlations have been marked with asterisk. $\mathrm{P}<0.05$ taken as significance level.

\section{Discussion}

Our results show the lack of influence of TLC and PC on the SSS density, which may be due to their concentration being much less than RBCs (leucocytes) and much smaller size than RBCs (platelets). Although this has not been explicitly studied in contemporary literature, our result lends itself to scientific explanation. The significant correlation between $\mathrm{Hb}$ and SSS densities has already been demonstrated by Black et al, wherein they found a significant correlation coefficient of 0.5 between mean SSS density using circular ROI and haematocrit [1]. A similar study done on non-contrast enhanced CT scan of abdomen showed better correlation coefficients for aorta $(r=0.64)$ and inferior vena cava (IVC) $(r=0.57)$ than the SSS compared to both our and Black's study [3]. This may be due to increased flow rates due to smaller caliber of SSS compared to IVC and aorta. Although we did obtain basilar artery density, it was not used for calculation as beam hardening effects of posterior fossa and calcifications, if any, could lead to erroneous findings.

We tried to explore the effect of two different methods of CT density calculation (circular and triangular ROIs) in the SSS. The circular method values were seen to be much better correlated with $\mathrm{Hb}$ values than the triangular method which could be attributed to various reasons. Firstly, it may be due to the higher concentration of RBCs in the centre of the SSS than at the peripheries owing to variable shear rates on the RBCs in centre compared to peripheries of the vessel. Secondly, the effect of bone and dural density on the values of the triangular ROI cannot be discounted. This is confirmed by the fact that the maximum signal densities were found to be significantly higher in the triangular ROIs (mean difference $3.59 \pm 4.12 \mathrm{HU}$, $\mathrm{p}<0.001$ ). Thirdly, in cases where there is tracking of blood along the dural wall (eg. subdural hematoma), differentiating the outline may prove tricky. The regression equation derived for calculation of $\mathrm{Hb}$ from $\mathrm{Cmean}$ explained the variability in the dependant variable quite poorly $(\mathrm{R} 2=0.175)$. This may be due to the fact that the flow velocities in SSS vary with the intracranial pressure, which was not included in the data collection. The variable flow velocities have a significant effect on the aggregation of RBCs at centre of the lumen and hence the signal densities as borne out by the different mean densities in IVC and aorta observed in Collin's study [3,4]. Higher flow rates tend to reduce red cell aggregation and vice versa, which would decrease or increase the red cell concentration in the ROI independent of the $\mathrm{Hb}$ concentration and hence inject significant variability [4]. This will also explain the high limits of agreement seen on the Bland Altman plot even though the mean difference between the observed and predicted values was quite low (Figure 3). Limitations

The study suffers with limitation of being retrospective in nature and non availability of SSS blood flow velocities or intracranial pressure for more accurate determination of variability in SSS density.

\section{Conclusion}

Although one may argue the utility of this technique, due to availability of point of care $\mathrm{Hb}$ estimation and rapid blood analyzers for estimating values, this method may just add to the repertoire of techniques of blood transfusion requirement estimation in cases of TBI, where the Hb levels are not available 
immediately. The appeal of the findings of this study is the simplicity of the method for the practicing anesthesiologist or radiologist, and the rapidity of estimation which is paramount while taking up a patient for emergency decompression of an intracranial hematoma.

\section{Acknowledgment}

None.

\section{References}

1. Black DF, Rad AE, Gray LA, Campeau NG, Kallmes DF (2011) Cerebral venous sinus density on noncontrast CT correlates with hematocrit. Am J Neuroradiol 32(7): 1354-1357.

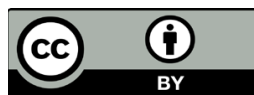

This work is licensed under Creative Commons Attribution 4.0 License

DOI: 10.19080/JAICM.2018.06.555686
2. Bishop JJ, Popel AS, Intaglietta M, Johnson PC (2001) Rheological effects of red blood cell aggregation in the venous network: A review of recent studies. Biorheology 38(2-3): 263-274.

3. Collins AJ, Gillespie S, Kelly BE (2001) Can computed tomography identify patients with anaemia? Ulster Med J 70(2): 116-118.

4. Ong PK, Namgung B, Johnson PC, Kim S (2010) Effect of erythrocyte aggregation and flow rate on cell-free layer formation in arterioles. Am J Physiol Heart Circ Physiol 298(6): H1870-H1878.

Your next submission with Juniper Publishers will reach you the below assets

- Quality Editorial service

- Swift Peer Review

- Reprints availability

- E-prints Service

- Manuscript Podcast for convenient understanding

- Global attainment for your research

- Manuscript accessibility in different formats

( Pdf, E-pub, Full Text, Audio)

- Unceasing customer service

Track the below URL for one-step submission https://juniperpublishers.com/online-submission.php 